\title{
Use of Umbilical Cord flap for Closure of Gastroschisis
}

\author{
Ferdous KMN ${ }^{1}$, Hasan MS'2 Kabir KA ${ }^{3}$, Zahid MK ${ }^{4}$, Islam MK ${ }^{5}$, Hasanuzzaman M $^{6}$
}

Conflict of Interest: None

Received: $27-02-2018$

Accepted: $02-05-2018$ www.banglajol.info/index.php/JSSMC

Key Words:

Umbilical Cord flap,

Gastroschisis.

\begin{abstract}
Background: Primary reduction of swollen oedematous viscera in gastroschisis is difficult, results abdominal compartment syndrome and associated with poor prognosis. Use of umbilical cord flap reduce intra-abdominal pressure and results batter outcome.
\end{abstract}

Objective: This retrospective study was done to evaluate the outcome of gastroschisis patient in whom umbilical cord flap covering was given.

Methods: Clinical records of the patients of gastroschisis were evaluated retrospectively during the period of July 2014 to June 2017, whom the abdominal wall defect ware covered with umbilical cord flap. After reduction of bowel into the abdomen as much as possible without pressure, the remaining eviscerated intestine is covered by the longitudinally split umbilical cord if the adequate length was available.

Results: Total 108 neonates were admitted with gastroschisis. Out of them, in 27 neonates umbilical cord flap were used. In 16 cases, abdominal defect was healed completely. Eight patients developed ventral hernia required secondary repair operation when 1 year 6 months old. All 24 survived children were followed up for 6 months to 2 years 6 months. Mean follow up time was $1.7 \pm 1.3$ years.

Conclusion: Umbilical cord flap coverage could be a better technique in repair of gastroschisis with oedematous gut, where postoperative NICU facilities is limited.

[J Shaheed Suhrawardy Med Coll 2018; 10(1): 47-50] DOI: http://dx.doi.org/10.3329/jssmc.v10i1.38904

\section{Introduction}

Gastroschisis is a congenital defect in the abdominal wall usually to the right to the umbilical cord, through which bowel and occasionally other organs herniated outside the abdomen with no covering membrane or sac. ${ }^{1}$ During the past decades, the incidence of gastroschisis is

1. Dr. Kazi Md. Noor-ul Ferdous, Assistant Professor, Division of Pediatric Surgery, Bangladesh Institute of Child Health and Dhaka Shishu (Children) Hospital

2. Dr. Md. Samiul Hasan, Assistant Professor, Division of Pediatric Surgery, Bangladesh Institute of Child Health and Dhaka Shishu (Children) Hospital

3. Dr. Kh. Ahasanul Kabir, Registrar, Division of Pediatric Surgery, Bangladesh Institute of Child Health and Dhaka Shishu (Children) Hospital.

4. Dr. Mirza Kamrul Zahid, Associate Professor, Department of Pediatric Surgery, Shaheed Suhrawardy Medical College \& Hospital, Dhaka

5. Prof. M Kabirul Islam, Professor, Division of Pediatric Surgery, Bangladesh Institute of Child Health and Dhaka Shishu (Children) Hospital

6. Dr. Md. Hasanuzzaman, Registrar, Department of Pediatric Surgery, Shaheed Suhrawardy Medical College \& Hospital, Dhaka

Correspondence: Dr. Kazi Md. Noor-ul Ferdous,MBBS, M.S. Dhaka Shishu (Children) Hospital Dhaka, Bangladesh. Email:kmnferdous@gmail.com increasing worldwide reaching values from incidence varies from 1 in 4000 to 1 in 10000 live birth with a strong association with young maternal age. ${ }^{2,3}$ The gold standard surgery for gastroschisis is still to be identified. The management principles for the correction of gastroschisis are, to reduce the viscera into the abdomen and then attempt of fascial closure. This is feasible only in twothirds of cases $^{4}$. In developed centers prenatal diagnosis improved the outcome gastroschisis by optimizing time, place and mode of delivery. In low-resource countries, prenatal diagnosis is almost absent. After delivery these neonates present with exposed, swollen and edematous viscera and patients were in severe hypovolemia \& hypothermia. ${ }^{5}$ Primary reposition of these swollen and edematous viscera without raising intra-abdominal pressure is almost impossible and if done became dangerous due to development of abdominal compartment syndrome. 3,5 For these reasons, some authors recommend formation of silo and then routine staged reduction. 6,7

In the early $1970 \mathrm{~s}$, use of the umbilical cord as autogenic material was shown to be useful in abdominal wall defects. The human umbilical cord was associated with the least inflammatory reaction, the lowest incidence of wound dehiscence, the shortest healing time and the highest 
number of survivors in the repair of experimentally created abdominal wall defects. ${ }^{8}$ In our center, we used umbilical cord flap in some patients with gastroschisis where primary repair was not possible.

\section{Method}

During the period of three years (July 2014 to June 2017), we reviewed all data records of operating room and follow up center in the Division of Pediatric Surgery, Dhaka Shishu (children) Hospital, Dhaka. In this retrospective study, the cases of gastroschis, whom covered with umbilical cord flap are included.

Immediate after admission of the neonate with gastroschisis, was managed by protecting the eviscerated bowel in a plastic bag, decompressing the stomach by a nasogastric tube and keeping the baby warm. The newborn was transferred to the operating room(OR) after stabilized haemodynamically. Under general anaesthesia, after warm saline compression, the exposed bowel was carefully inspected for bowel ischemic, perforation, atresia and other malformations. The bowel was then decompressed by evacuating the meconium to reduce the volume. Digital anal dilatation and rectal irrigation was given with warm saline to facilitate evacuation. Catheterization was done.

A vertical incision (about $2-3 \mathrm{~cm}$ ) was made from the defect towards upwards. Reduction of the gut into the abdomen and primary fascial colosure tried. If the abdomen was too tight the reduction procedure was stopped to prevent abdominal compartment syndrome. In the patient, whom the umbilical cord was remain more than $10 \mathrm{~cm}$, it was used to cover the external bowel. The umbilical cord was split longitudinally to open, and sutured around the defect and incision with the fascia and skin. The vessels inside the umbilical cord need not to remove. The edges of the split umbilical cord were sutured to one another as closure of the defect.

Nosogastric (NG) tube were kept for 7-10 days to gastrointestinal decompression and stopped according to the collection. Test feeding started with 2-5 cc normal saline/2hrly. If test meal tolerated, $3-5 \mathrm{cc} / 2 \mathrm{hrly}$ exprssed breast milk was given through NG tube. Oral feeding began 5 mintues/ 2 hrly according to patient's sucking reaction and feeding gradually increased.

\section{Results}

In the Department of pediatric surgery, at Dhaka Shishu (Children) Hospital during the period total 108 Neonates were admitted with gastroschisis. Out of them, in 27 neonates we have used umbilical cord flap in the management of gastroschisis where primary reduction was not possible. The gender distribution and mortality shown in figure- 1 and 2 .

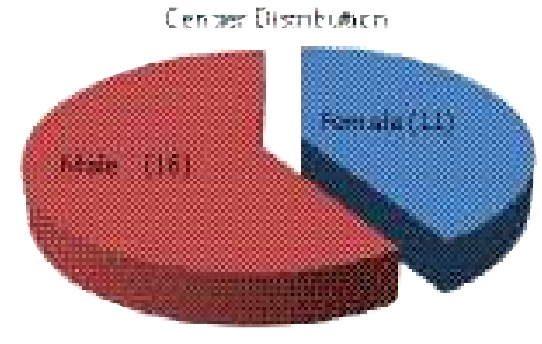

Fig-1: Gender distribution

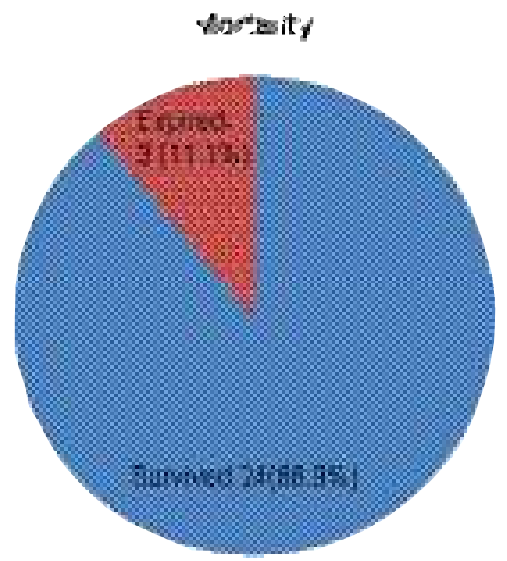

Fig- 2: Mortality

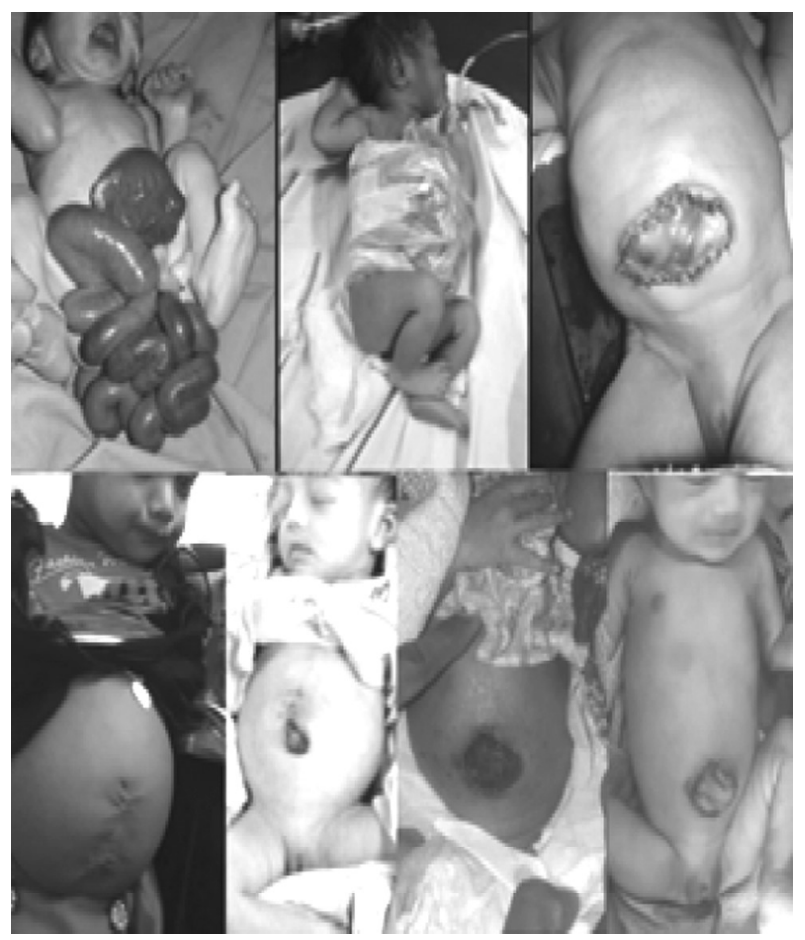

Fig-3: Serial photographs of a patient with gastroschisis (clockwise)- at the time of admission, after plastic sheet wrapping, use of umbilical cord flap as covering, 7th POD, 15th POD, After 1 month, at the age of 2 years. 
Mean gestational age, mean age at presentation, birth weight, length of umbilical cord, length of hospital stay was tabulated in Table-1.

\section{Table 1}

Distribution of variables

\begin{tabular}{lcc} 
Variables & Mean \pm SD & Range \\
\hline Gestational age (Weeks) & $34.4 \pm 1.7$ & $28-37$ \\
Age at presentation (days) & $1.4 \pm 1.8$ & $1-5$ \\
Birth weight (Kg) & $2.1 \pm 0.3$ & $1.4-2.6$ \\
Cord length (cm) & $15.4 \pm 3.3$ & $10-35$ \\
Hospital stay (Days) & $18.1 \pm 2.4$ & $14-25$ \\
\hline
\end{tabular}

Only 2 of these 27 gastroschisis patients were diagnosed prenatally. Twenty five of them were delivered in the hospital by caesarian section and rest were home delivery.

Five of 27 patients needs ventilator support postoperatively. Three patients of these were expired due to low birth weight and sepsis. In 16 cases, abdominal defect was healed completely. Eight patients developed ventral hernia required secondary repair operation when 1year 6 months old. All 24 survived children were followed up for 6 months to 2 years 6 months [Figure-3]. Mean follow up time was $1.7 \pm 1.3$ years.

\section{Discussion}

The first objective of the management of gastroschisis should be the primary closure of abdominal wall defects to ensure best protection of the viscera, which is not possible almost in one third patients ${ }^{4}$. Since late 1960s, in giant abdominal wall defects, staged closure is a widely accepted practice using Teflon sheets and then Silastic sac. ${ }^{9,10}$

The primary closure is not always possible for the development of abdominal compartment syndrome due to the presence of viscero-abdominal disproportion, and it represents a critical problem, specially in low-resource countries, where surgeons could not avoid silos. ${ }^{11}$ The risks of silo placement include infection, suture line disruption, bowel adhesions due to the synthetic material, or mechanical complications caused by the ring. ${ }^{12,13}$

Koltai used umbilical cord flap with temporary coverage of the eviscerated bowel like a silo, which facilitates continuous, gentle reduction without any adhesions to the bowel and without infections. ${ }^{14}$ Thus, it combines the advantages of a staged procedure with the benefit of autogenic materials results in ventral hernia before reconstruction of the fascia and skin. ${ }^{15}$
In Gastroschisis neonate, number of male is predominate than female. ${ }^{4,5}$ We found the same in our study, but Bradnock $\mathrm{T} \mathrm{J}$ et al found opposite. ${ }^{16}$

Only 2 (of 27) patients in our study diagnosed prenatally. Which is similar to Hasan SM et al study. They mention, this is due to less public awareness about prenatal care and screening, limited experience of radiologists and primary care giver at rural area might also be a contributing bad prognostic factor in a developing country. ${ }^{5}$ In the developed centers prenatally diagnosed cases are delivered in tertiary centers and after delivery these neonates undergo prompt resuscitation which is associated with the better outcome. ${ }^{2,17}$ Most authors urges earliest possible repair of gastroschisis for the best outcome and they do it within 5 hours of delivery, even just after delivery. ${ }^{2}$

In the low-resource country, due to lack of proper neonatal transport facilities gastroschisis patients from periphery presented to the hospital with exposed, swollen, edematous viscera and with severe hypovolemic hypothermia. ${ }^{5}$ Which made the reposition of the viscera and primary closure very difficult. Hence silo was performed for staged repair in most patients. ${ }^{17,18}$

Several studies reported better outcome using preformed silo. ${ }^{4,19}$ Low-resource country like us, maintenance of a silo is very difficult as almost all of this patients developed sepsis and other complications, which were associated with poor outcome. ${ }^{5}$

In this study, we used umbilical cord flap to cover the exposed intestine where reduction and primary closure was not possible and the result was good. The authors who used umbilical cord to cover the abdominal wall defect in gastroschisis found same result. ${ }^{15,20,21}$ All the patients of those studies survived. This is because of advanced NICU care and nutritional support. ${ }^{22}$ Three of our studied patients expired. As we could not provide NICU support for all those patients and prolonged parenteral nutrition facilities are not available in our setup.

To ensure the neonate with gastroschisis for timely and effective use of their own umbilical cord flap Liu F et al advised to use the media, meetings and to maintain good and effective communication with the obstetrics and gynecology colleagues, they must reserve $8-10 \mathrm{~cm}$ umbilical cord, in the neonate with abdominal wall defect. ${ }^{21}$

\section{Conclusion:}

Umbilical cord flap coverage could be a safe and better technique in repair of gastroschisis with oedematous gut, even in simple cases. It is very effective to prevent the disastrous outcome of abdominal compartment syndrome. 
The procedure reduce the economic burden of the parents where postoperative NICU facilities is limited.

\section{References}

1. Daniel J, Ledbetter, Congenital Abdominal Wall Defects and Reconstruction in Pediatric Surgery Gastroschisis and Omphalocele. Surg Clin N Am. 2012;92: 713-727

2. Quirk JG, Fortney J, Collins H B, West J, Hassad SJ, Wagner C. Outcome of newborns with gastroschisis: the effects of mode of delivery, site of delivery and interval from birth to surgery. American Journal of Obstetrics and Gynecology. 1996; 174: 1134-38.

3. Loane M, Dolk H, Bradbury I. Increasing prevalence of gastroschisis in Europe 1980-2002: a phenomenon restricted to younger mothers? Paediatr Perinat Epidemiol. 2007;21(4):363-9.

4. Owen A, Marven S, Johnson P et al. Gastroschisis: a national cohort study to describe contemporary surgical strategies and outcomes. J Pediatr Surg. 2010; 45: 1808-1816

5. Hasan MS, Ferdous KMN, Aziz A, Ali A, Biswas PK. Outcome of Gastroschisis in a Developing Country: Where to Focus? Global Journal of Medical Research. 2017;,Vol. 17(1):25-28

6. Pastor AC, Phillips JD, Fenton SJ et al. Routine use of a Silastic spring- loaded silo for infants with gastroschisis: a multicenter randomized controlled trial. J Pediatr Surg. 2008; 43: $1807-1812$

7. Rao SC, Pirie S, Minutillo C, Gollow I, Dickinson JE, Jacoby P. Ward reduction of gastroschisis in a single stage without general anaesthesia may increase the risk of short-term morbidities: results of a retrospective audit. J Paediatr Child Health. 2009 Jun;45(6):384-8.

8. Heaton FC, Thomas Jr CG, Owen J. The use of umbilical cord for recon- struction of abdominal wall defects. Surg Forum. 1970; 21: 56-57

9. Schuster SR. A new method for the staged repair of large omphaloce- les. Surg Gynecol Obstet. 1967; 125: 837-850

10. Allen RG, Wrenn Jr EL. Silon as a sac in the treatment of omphalocele and gastroschisis. J Pediatr Surg. 1969; 4: 3-8
11. Wright NJ, Zani A, Ade-Ajayi N. Epidemiology, man- agement and outcome of gastroschisis in Sub-Saharan Africa: Results of an international survey. Afr J Paedi- atr Surg. 2015;12:1-6.

12. Linsdale N, Hill R, Gull-Zamir S et al. Staged reduction of gastroschisis using preformed silos: practicalities and problems. J Pediatr Surg. 2009; 44: 2126-2129

13. Ryckman J, Aspirot A, Laberge JM et al. Intestinal venous congestion as a complication of elective silo placement for gastroschisis. Semin Pediatr Surg. 2009; 18: 109-112

14. Koltai JL. Umbilical cord plasty for temporary reconstruction of giant congenital abdominal wall defects. (Article in German) Zentralbl Kinderchir. 1995; 4: 81-84

15. Werbeck R., Koltai J., Umbilical Cord as Temporary Coverage in Gastroschisis. ur J Pediatr Surg. 2011; 21: 292- 295

16. Bradnock TJ, Marven S, Owen A, Johnson P, Kurinczuk J, Spark P. et al. British Medical Journal. 2011; 343: 01-09 doi: 101136/bmj.d6749.

17. Driver CP, Bianchi BA, Doig CM, Dickson AP, Bowen J. The contemporary outcome of gastroschisis. Journal of Pediatric Surgery. 2000; 35(12): 1719-23.

18. Snyder CL. Outcome analysis of Gastroschisis. Journal of Pediatric Surgery. 1999; 34(8): 1253-56.

19. Schlatter M, Norris K, Uitvlugt N, Decou J, Connors R. Improved outcome in the treatment of gastroschisis using a preformed silo and delayed repair approach. Journal of pediatric surgery. 2003; 38(3): 459-64.

20. Briganti V, Luvero D, Gulia C, Piergentili R, Zaami S, Buffone EL, Vallone C, Angioli R, Giorlandino C, Signore F. (2017): A Novel Approach in the Treatment of Neonatal Gastroschisis: A review of the Literature and a Single Center Experience, The Journal of Maternal-Fetal \& Neonatal Medicine, DOI: $10.1080 / 14767058.2017 .1311859$

21. Liu F, Ma T, Zeng Z, Zhang J, Zhang N, Yuan H. Autologous umbilical cord patch repair 11 cases of congenital gastroschisis. Biomedical Research. 2017; 28 (22): 9864-9866

22. Watanabe S, Suzuki T, Hara F, Yasui T, Uga N, Naoe A. Omphalocele and gastroschisis in newborns: over 16 years of experience from a single clinic. J Neonat Surg. 2017; 6: 27. 